\title{
Vegetative Compatibility Groups within Fusarium oxysporum f. sp. cepae in Hokkaido-Japan
}

\author{
WIDODO $^{1 *}$, NORIO KONDO², KIROKU KOBAYASHI ${ }^{2}$, ANDAKIRA OGOSHI ${ }^{2}$ \\ ${ }^{1}$ Department of Plant Protection, Faculty of Agriculture, Institut Pertanian Bogor, \\ Kampus Darmaga, Bogor 16680, Indonesia \\ ${ }^{2}$ Graduate School of Agriculture, Hokkaido University, Sapporo 060-8589, Japan
}

\begin{abstract}
In Hokkaido, Fusarium basal rot, caused by Fusarium oxysporum f. sp. cepae is one of the important constrains since 1973 which contributes to a significant loss in onion production, either in the fields or during storage. Development of resistant cultivars is suggested as one of the effective control measures against the disease, however, this should be accompanied with the better understanding of the pathogen's population dynamics. This study was performed to investigate the population structure of $F$. oxysporum f. sp. cepae based on vegetative compatibility groupings (VCGs). Vegetative compatibility groups of $F$. oxysporum f. sp. сераe were characterized using nitrate non-utilizing (nit) mutants. Four VCGs and 2 single self-compatible (SSC) isolates were identified among 48 isolates, designated as VCG 0420 (33 isolates), 0421 (9 isolates), 0422 (2 isolates), 0423 (2 isolates), and 042-(2 isolates). VCG 0420, to which 4 ATCC isolates out of 6 belonged, was the predominant group within the growing region encompassing Hokkaido Japan. VCGs 0421 and artificial VCG 042- were found less frequently. Four isolates from Welsh onion were not compatible with any recovered VCGs and were assigned to 2 distinct VCGs (VCG 0422 and 0423).
\end{abstract}

Key words: Allium cepa, Fusarium basal rot of onions, Fusarium oxysporum f. sp. cepae, population

Hokkaido, the northernmost island of Japan, has the largest area under onion cultivation (Allium cepa) and accounts for $48 \%$ of national production. Fusarium basal rot, caused by Fusarium oxysporum f.sp. cepae, is an important soilborne disease of onion which occurs in Hokkaido. This fungus also causes seedlings damping-off and wilt. This disease was first reported in Japan in 1911, in the Ishikari district of western Hokkaido, but had no significant economic impact for many years (Kodama 1983). In 1970, the disease was reported in some areas of the central and eastern parts of Hokkaido i.e. Furano and Kitami (Kodama et al. 1974). By 1973, the disease was observed in most of the onion fields in Hokkaido (Kodama et al. 1974).

Although treating seedlings with fungicide $(1-2 \%$ benomyl) prior to transplantation has significantly reduced losses (Kodama 1983), the planting of resistant onion cultivars has been suggested as a valuable control measure (Abawi and Lorbeer 1971; Simizu and Nakano 1995; Thornton and Mohan 1996). Often, however, the use of cultivars resistant to $F$. oxysporum is compromised by the appearance of new pathogenic strains. F. oxysporum's ability to overcome host resistance may be related to its various strains existence and unstable genetic character (Abawi and Lorbeer 1965; Ploetz and Correll 1988; Jacobson and Gordon 1991). Since pathogens must constantly adapt to changes in their environment to survive (Abawi and Lorbeer 1972), an understanding of their population dynamics would be helpful in developing resistant cultivars.

Puhalla (1981) first made efforts to differentiate and classify formae speciales of $F$. oxysporum isolated from various plant species into vegetative compatibility groups (VCGs), using nitrate non-utilizing (nit) mutant (generated on media containing chlorate) that lacked the ability to use nitrate as a nitrogen source. This was refined by Correll et al. (1987). Since that time, numerous investigators have

\footnotetext{
*Corresponding author, Phone/Fax: +62-251-8423048, E-mail: widodo@ipb.ac.id
}

classified F. oxysporum isolated from various host plants into distinct VCGs using nit mutants (Elmer and Stephens 1989; Larkin et al. 1990; Elias and Schneider 1991; Katan et al. 1991; Loffler and Rumine 1991; Venter et al. 1992; Fiely et al. 1995; Woudt et al. 1995; Woo et al. 1996; Harveson and Rush 1997; Kondo et al. 1997; Lori et al. 2004; Vakalounakis et al. 2005). Five VCGs of $F$. oxysporum f. sp. cepae from onion have been identified in Colorado, USA, and one of the VCGs was present in all three regions of Colorado (Swift et al. 2002). The use of VCGs has also been performed to determine the diversity of nonpathogenic populations of $F$. oxysporum isolated from carnation fields in Argentina (Lori et al. 2004). Beside for determining the VCGs of Fusarium, the use of nit mutant combining with selective media was also useful in studying population dynamics of pathogenic F. oxysporum f. sp. spinaceae in soil (Takehara et al. 2003). In the special case of $F$. oxysporum, the vegetative compatibility group (VCG) approach can be an effective diagnostic technique when the number of VCGs in formae speciales of interest is known to be relatively small since the tester strains needed are usually easy to obtain (Summerell et al. 2003).

The objectives of this study were to investigate the population type and distribution of F. oxysporum f. sp. сераe from Hokkkaido Island, Japan, based on vegetative compatibility groups.

\section{MATERIALS AND METHODS}

Collection of Isolates and Pathogenicity Testing. Fusarium oxysporum were collected from infested-field-soil or diseased onion stem-plates from 6 locations (Mikasa, Furano, Kitami, Kunnenpu, Tsubetsu, and Tanno) in Hokkaido. Additional isolates were obtained from individuals (4 isolates of Welsh onion from Yakumo and 3 isolates of onion from Furano supplied by Dr. H. Abe and Dr. F. Kodama, respectively) and culture collections (American Type Culture 
Collection). Infected stem- plates with brown discoloration were surface sterilized using cotton wipes wetted with $70 \%$ ethanol and allowed to dry. Each stem-plate was cut with a sterile knife into small blocks ( $\left.2 \times 2 \times 2 \mathrm{~mm}^{3}\right)$. Five pieces of each bulb were placed in Komada's medium (KM) (Komada 1975) and incubated at $26^{\circ} \mathrm{C}$ for 5 to 7 days. The entire stemplates were used for isolates recovered from damped-off seedlings. Soil dilution was used for isolation from soils. After 5-7 days incubation colonies, which were tentatively identified as F. oxysporum on the basis of colony morphology, were transferred to fresh plates of KM. Spores from 5-7-day-old cultures growing on KM were streaked onto water agar $\left(20 \mathrm{~g} \mathrm{l}^{-1}\right)$. After $18 \mathrm{~h}$ a single germinated spore was removed from the water agar and transferred to potato sucrose agar (PSA: potato 200 g, sucrose 15 g, agar 20 g, and distilled water $1000 \mathrm{ml}$ ). Identification was based on mycological characteristics as described by Nelson et al. (1983).

Pathogenicity Tests. Each isolate was tested for pathogenicity using a susceptible onion cultivar (Kitawase No. 3). A conidial suspension was prepared from 7-10-dayold cultures growing on PSA plates and used as inoculum. The suspension was filtered through 4 layers of cheesecloth to separate conidia from mycelium and adjusted to $1.0 \times 10^{6}$ spores $\mathrm{ml}^{-1}$. Six- to 8-week-old seedlings were pulled up and shaken to remove excess soil, and then cut $5 \mathrm{~mm}$ below their stem plate. The roots of 15 seedlings were dipped for $24 \mathrm{~h}$ into $20 \mathrm{ml}$ of a conidial suspension and then transplanted into a soil (Pot-ace, Katakura Chikkarin K. K., Tokyo, Japan)/ vermiculite mixture (3:1 v/v) in 12-cm-diameter plastic pots in triplicate. Each pot contained 5 seedlings. Other seedlings were dipped in sterile water and planted as above to act as controls. The number of damping-off plants was recorded over 5 weeks after transplantation. After 5 weeks, longitudinal sections of unwilted plants were observed for discoloration of stem-plates. These tests were conducted in a greenhouse with temperatures ranging from 20 to $28^{\circ} \mathrm{C}$. Of the isolates that induced plant damping-off more than $30 \%$ were considered as pathogenic. Re-isolation from the experimentally symptomatic plants was performed to verify that the recovered isolates had the same characteristics as the isolates in the initial inoculation.

Recovery of Nitrate Non-Utilizing (nit) Mutants. Mutants were selected using the method of Puhalla (1985). Each isolate of F. oxysporum was grown on PSA for 5-7 days at room temperature. Four small mycelial blocks $\left(2 \mathrm{~mm}^{3}\right)$ of the fungus were placed onto a plate containing corn-mealagar modified by adding $15 \mathrm{~g} \mathrm{l}^{-1} \mathrm{KClO}_{3}$ (CMAC). Many isolates failed to form mutants on this medium, so chlorate $\left(\mathrm{KClO}_{3}\right)$ concentrations were often doubled to $30 \mathrm{~g} \mathrm{l}^{-1}$. The plates were incubated at $26{ }^{\circ} \mathrm{C}$ for 15 days and inspected periodically for the appearance of fast growing hyphae developing from the initial colony. These fast growing hyphae were then transferred to a minimal medium (MM) that contained $\mathrm{NaNO}_{3}\left(2 \mathrm{~g} \mathrm{l}^{-1}\right)$ as the sole nitrogen source (Puhalla 1985). Mutants that grew on MM as thin expansive colonies with no aerial mycelium were considered as nit mutants.

Nit Mutant Phenotypes. The phenotypic classes of all nit mutants were determined by their growth on media containing nitrate $\left(2 \mathrm{~g} \mathrm{l}^{-1}\right)$, nitrite $\left(0.5 \mathrm{~g} \mathrm{l}^{-1}\right)$, hypoxanthine $(0.2$ $\left.\mathrm{g} \mathrm{l}^{-1}\right)$, or ammonium tartrate $\left(1 \mathrm{~g} \mathrm{l}^{-1}\right)$ as the sole nitrogen source (Correll 1991). A small block of each mutant colony was transferred onto each medium. The plates were incubated as described above and colony growth was scored relative to the parental wild-type after 4 days growth. The nit mutants were placed into phenotypic classes (Klittich and Leslie 1988; Correll 1991) based on their ability to utilize the various nitrogen sources (Fig 1).

Complementation Test. Prior to complementation tests among isolates, the vegetative self-compatibility of each isolate was examined by the method of Jacobson and Gordon (1988). Ten isolates were initially selected for vegetative compatibility tests. They were paired in all possible combinations and grown on minimal medium to determine the number of vegetative compatibility groups (VCGs). Vegetatively compatible nit mutants that carry the mutated gene on different loci may complement one another by the formation of a dense aerial wild-type mycelium at the position where mycelia of nit1 and NitM colonies touch. A NitM from one isolate in each of the VCGs thus identified was selected to serve as a tester. After VCGs were established for the initial 10 isolates, the remaining isolates were treated in the same manner. For isolates that did not match with any of the established VCGs, a tester for a second group was obtained and the procedure was repeated.

\section{RESULTS}

When the isolates of $F$. oxysporum inoculated into cultivars Kitawase No. 3 using the root dip method were examined, some of them induced a progressive yellowing and die back from the tips of their leaves. In these cases the aerial part died completely within two or three weeks after inoculation. All the isolates inducing such symptom were taken to be as F. oxysporum f. sp. cepae based on the description of Kodama (1983). The degree of disease incidence induced within isolates having this symptom varied from $20-100 \%$. A total of 38 isolates of F. oxysporum pathogenic to onion and 173 nonpathogenic isolates were recovered from soil samples and diseased onion bulbs (Table 1).

Table 1 Geographical location and pathogenicity tests of isolates of Fusarium oxysporum collected from onion fields

\begin{tabular}{|c|c|c|c|c|c|}
\hline Location & Source (year) & $\begin{array}{l}\text { F. oxysporum population } \\
\text { (cfu g } \text { dry soil) }^{-1}\end{array}$ & No. of isolates tested & No. of pathogenic isolates & No. of nonpathogenic isolates \\
\hline Mikasa & Soil (1996) & $5.3 \times 10^{3}$ & 77 & 11 & 66 \\
\hline Furano & Bulb (1997) & & 53 & 6 & 47 \\
\hline Tanno & Soil (1997) & $1.2 \times 10^{3}$ & 26 & 2 & 24 \\
\hline Kitami & Soil (1997) & $1.9 \times 10^{3}$ & 24 & 3 & 21 \\
\hline Tsubetsu & Soil (1997) & $0.4 \times 10^{3}$ & 6 & 1 & 5 \\
\hline Kunnenpu & Bulb (1997) & & 25 & 15 & 10 \\
\hline
\end{tabular}


Nit mutants emerged from restricted growth on corn meal agar medium amended with chlorate after 4-15 days. Most of the isolates produced mutants when generated on medium containing chlorate $15 \mathrm{~g} \mathrm{l}^{-1}$. Some other isolates had to be generated on media containing $30 \mathrm{~g} \mathrm{l}^{-1}$ to obtain the mutants. All the isolates used in this study are able to produce all the 3 mutant phenotypes as indicated on their ability on using different nitrogen source (Fig 1).

The 38 isolates of $F$. oxysporum $\mathrm{f}$. sp. cepae recovered from soils in Hokkaido Island-Japan along with the ten known isolates of F. oxysporum f. sp. cepae were grouped into 4 distinct VCGs and 2 SSC isolates based on complementation of nit1 and NitM mutants. They consisted of one large VCG with 33 members, including 4 isolates from ATCC. This one large group was first reported by Yoo et al. (1993), and was numbered using Puhalla's numbering system (Puhalla 1985) as VCG 0420 by Katan and Di Primo (1999). Therefore, the three other VCGs and two isolates of single self-compatibility were an additional group for this formae speciales. These three other VCGs were then designated as VCG 0421 (9 isolates), VCG 0422 (2 isolates), and VCG 0423 (2 isolates), respectively. The two isolates of SSC with members of ATCC 11850 and ATCC 46076 were assigned to artificial VCG 042(Table 2). The population of F. oxysporum f. sp. cepae assigned as VCG 0420 was mostly distributed throughout the sampling area in Hokkaido (Fig 2).

Among the ATCC isolates tested, ATCC 46076 and ATCC 46077 were originally isolated from Hokkaido, Japan, in the 1970's. Complementation assays of ATCC 46077 placed it into the largest vegetative compatibility group, while ATCC 46076 was unable to form heterokaryons with any other isolates collected from Hokkaido, Japan (Table 2). The ATCC 46076 isolate was also not vegetatively compatible with the most predominant isolates collected from Hokkaido in this study as showed in the complementation tests with the isolate SM 025 (Fig 3).

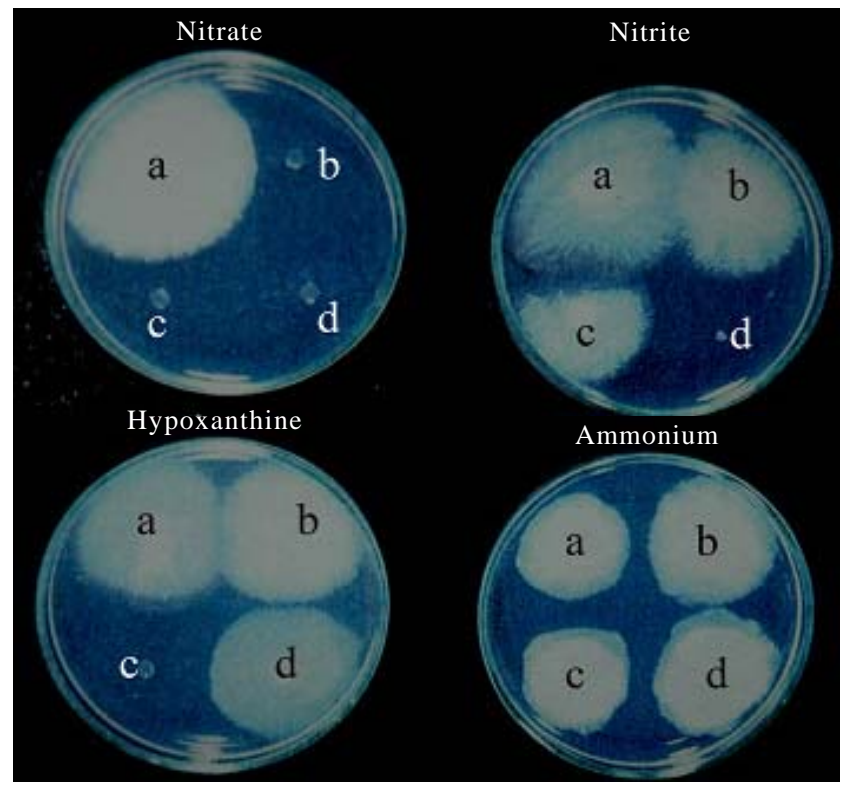

Fig 1 Growth of wild-type parental strain (SM 025) of Fusarium oxysporum f. sp. cepae and its three nitrate non-utilizing (nit) mutant phenotypes on four different nitrogen resources. a. Wild-type, b. Nit 1 , c. NitM, d. nit 3. Dense aerial mycelium growth indicating the ability on using nitrate resources.
Table 2 Vegetative compatibility groups among isolates of Fusarium oxysporum f. sp. cepae

\begin{tabular}{|c|c|c|}
\hline VCGa & Source/Origin & No. of isolates \\
\hline \multirow[t]{6}{*}{0420} & Mikasa & $\begin{array}{l}5 \text { (SM 024, SM 025, 1-1026, 1-2015, 1- } \\
\text { 2017) }\end{array}$ \\
\hline & Furano & $\begin{array}{l}6^{*} \text { (NK 041, TR 001, TR 005, 93-37-3, 93- } \\
\text { 37-4, nKF 900) }\end{array}$ \\
\hline & Kitami & 2 (KTM 517, KTM 519) \\
\hline & Kunnenpu & $\begin{array}{l}15 \text { (KARS 9801, Kn-O-01, Kn-O-02, Kn- } \\
\text { O-04, Kn-O-06, Kn-O-10, Kn-O-11, } \\
\text { Kn-O-12, Kn-O-14, Kn-O-17, Kn-O- } \\
\text { 18, Kn-O-19, Kn-H-03,989-01, 989- } \\
02 \text { ) }\end{array}$ \\
\hline & Tsubetsu & $1(9812-04)$ \\
\hline & ATCC & $\begin{array}{l}4 \text { (ATCC 11711, ATCC 46077, ATCC } \\
\text { 62592, ATCC 60768) }\end{array}$ \\
\hline \multirow[t]{3}{*}{0421} & Mikasa & $\begin{array}{l}\text { 6(SM 037, SM 044, SM 045, SM 046, MH } \\
\text { 019, 3-1024) }\end{array}$ \\
\hline & Kitami & 1 (KTM 503) \\
\hline & Tanno & 2(TN 98-01, K-3-19) \\
\hline 0422 & Yakumo & $2^{* *}(\mathrm{WO}-\mathrm{F}-41$ and WO-F-46) \\
\hline 0423 & Yakumo & $2^{* *}(\mathrm{WO}-\mathrm{F}-10$ and WO-F-34) \\
\hline $042-^{\mathrm{b}}$ & ATCC & 2 (ATCC 11850 and ATCC 46076) \\
\hline
\end{tabular}

*Including three isolates from Dr. F. Kodama (nKF-900, 93-37-3, and 93-37-4); ** Isolates of Welsh onion from Dr. H. Abe; ${ }^{a}$ VCG's are numbered according to Puhalla's numbering system as proposed by

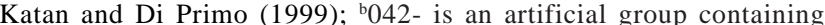
isolates that are single member of a VCG.

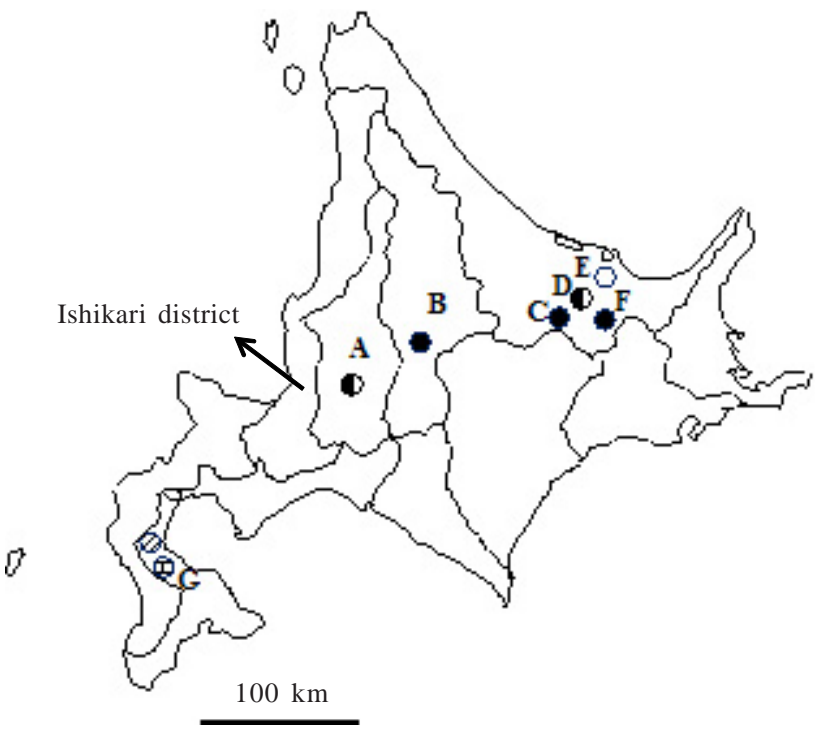

Fig 2 Distribution of Fusarium oxysporum f. sp. cepae population in Hokkaido based on vegetative compatibility groups. A. Mikasa, B. Furano, C. Kunnenpu, D. Kitami, E. Tanno, F. Tsubetsu, G. Yakumo. VCG 0420, VCG 0421, VCG 0420 and 0421, VCG 0422, VCG 0423.

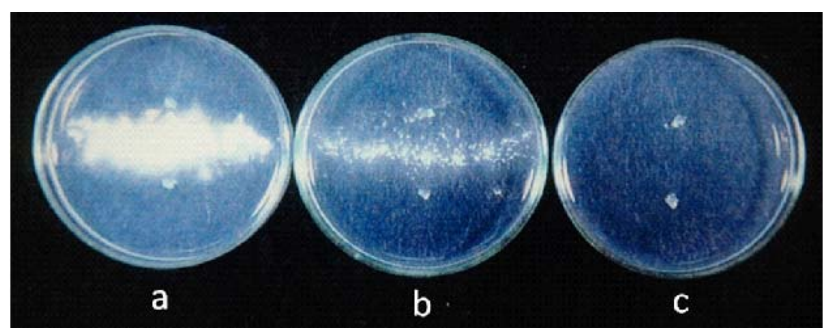

Fig 3 Heterokaryon formation between complementary nitrate non-utilizing mutants of Fusarium oxysporum f. sp. cepae on minimal medium containing nitrate as the sole source of nitrogen. a. Complementation reaction between isolate SM 025 and 1-1026, b. Complementation between isolate SM 025 and nKF 900, c. No complementation between isolate SM025 and ATCC 46076. 


\section{DISCUSSION}

Thirty eight isolates of F. oxysporum f. sp. cepae collected from seven locations in Hokkaido and 10 isolates from the ATCC which included 4 isolates from Hokkaido, were grouped into 4 VCGs and 2 SSC isolates. Within 42 isolates of $F$. oxysporum f. sp. cepae from Hokkaido, one predominant VCG containing 33 isolates was identified. The isolates obtained from onion were widely distributed across most of the sampling sites (Fig 1). The presence of this predominant group in different onion fields indicates that this population has been selectively maintained. A similar phenomenon has been observed for other formae speciales of F. oxysporum (Elias and Schneider 1991; Katan et al. 1996; Ahn et al. 1998). The other VCG of onions from Hokkaido (VCG 0421) and one of the members of artificial VCG 042- (ATCC 46076) may lack the competitive traits necessary to insure their dispersal and survival. These results also showed that population structure of F. oxysporum f. sp. cepae based on VCGs was dynamic over time as indicated by replacing the predominant population of Hokkaido's isolate in 1970's (ATCC 46076) grouped into VCG042- with the new group VCG 0420 identified in this study. The change population predominance of F. oxysporum f. sp. cepae in Hokkaido might be affected by the shift of onion cultivars planted and other abiotic factors.

Isolates within formae speciales are genetically similar, probably originating from a single pathogenic genotype or clonal origin. Kistler (1997) proposed that a VCG within a population of $F$. oxysporum indicates a distinct clonal lineage as reported by Harveson and Rush (1997) on F. oxysporum f. sp. betae. They showed that VCGs of F. oxysporum f. sp. betae represented distinct isolated populations indigenous to their respective areas. Other researchers (Bosland and Williams 1987; Woo et al. 1996), however, reported that the formae speciales they were investigating did not exhibit a correlation between VCG and geographical origin. Although welsh onion isolates tested in this study was not comprehensive, these isolates tended to be distinct VCGs from onion isolates and were found to be limited in their geographical origin. Swift et al. (2002) reported that 9 out of 19 F. oxysporum f. sp. cepae isolates collected from diseased onion in Colorado, USA were grouped into 4 different VCGs and were also found in the limited area as indicated in our study. The extent of the distribution in Hokkaido of VCGs 0422 and 0423, is still unclear, as we did not have an adequate sampling of Welsh onion isolates from other locations. It is possible that these VCGs are dispersed via seeds, seedlings, plant debris, and/or human activities. Therefore, it would be useful to monitor those groups that have the potential to cause a serious problem.

\section{ACKNOWLEDGEMENTS}

We would like to thank F. Kodama and J. Souma of the Kitami Agricultural Experimental Station, Hokkaido, Japan, who supplied the isolates and soil samples used in this study, and H. Abe of the Kamikawa Agricultural Experimental Station, Hokkaido, Japan, for providing the isolates from Welsh onion

\section{REFERENCES}

Abawi GS, Lorbeer JW. 1965. Cultural variability and pathogenicity of Fusarium oxysporum f. sp. cepae. Phytopathology 55:1051.

Abawi GS, Lorbeer JW. 1971. Reaction of selected onion varieties to infection by Fusarium oxysporum f.sp. cepae. Plant Dis Reptr 55:1000-1004

Abawi GS, Lorbeer JW. 1972. Several aspects of the ecology and pathology of Fusarium oxysporum f. sp. cepae. Phytopathology 62:870-876.

Ahn IP, Chung, HS, Lee YH. 1998. Vegetative compatibility groups and pathogenicity among isolates of Fusarium oxysporum f. sp. cucumerinum. Plant Dis 82:244-246.

Bosland PW, Williams PH. 1987. An evaluation of Fusarium oxysporum from crucifers based on pathogenicity, isozyme polymorphism, vegetative compatibility, and geographic origin. Can J Bot 65:2067-2073.

Correll JC. 1991. The relationship between formae speciales, races, and vegetative compatibility groups in Fusarium oxysporum. Phytopathology 81:1061-1064.

Correll JC, Klittich CJR, Leslie JF. 1987. Nitrate non-utilizing mutants of Fusarium oxysporum and their use in vegetative compatibility tests. Phytopathology 77:1640-1646.

Elias KS, Schneider RW. 1991. Vegetative compatibility groups in Fusarium oxysporum f. sp. lycopersici. Phytopathology 81:159162

Elmer WH, Stephens CT. 1989. Classification of Fusarium oxysporum f. sp. asparagi into vegetative compatibility groups. Phytopathology 79:88-93.

Fiely MB, Correll JC, Morelock TE. 1995. Vegetative compatibility, pathogenicity, and virulence diversity of Fusarium oxysporum recovered from spinach. Plant Dis 79:990-993.

Harveson RM, Rush CM. 1997. Genetic variation among Fusarium oxysporum isolates from sugar beet as determined by vegetative compatibility. Plant Dis 81:85-88.

Jacobson DJ, Gordon TR. 1988. Vegetative compatibility and selfincompatibility within Fusarium oxysporum f. sp. melonis. Phytopathology 78:668-772.

Jacobson DJ, Gordon TR. 1991. Fusarium oxysporum f. sp. melonis: A case study of diversity within a forma specialis. Phytopathology 81:1064-1067.

Katan T, Di Primo P. 1999. Current status of vegetative compatibility groups in Fusarium oxysporum: Supplement (1999). Phytoparasitica 27:273-277.

Katan T, Gamliel A, Katan J. 1996. Vegetative compatibility groups of Fusarium oxysporum from sweet basil in Israel. Plant Pathol 45:656-661.

Katan T, Zamir D, Sarfatti M, Katan J. 1991. Vegetative compatibility groups and subgroups in Fusarium oxysporum f. sp. radicislycopersici. Phytopathology 81:255-262.

Kistler HC. 1997. Genetic diversity in the plant-pathogenic fungus Fusarium oxysporum. Phytopathology 87:474-479.

Klittich CJR, Leslie JF. 1988. Nitrate reduction mutants of Fusarium moniliforme (Gibberella fujikuroi). Genetics 118:417-423.

Kodama F. 1983. Studies on basal rot of onion caused by Fusarium oxysporum f. sp. cepae and its control. Rep Hokkaido Pref Agric Exp Stn No. 39. p 15.

Kodama F, Oyama M, Takakuwa M. 1974. The occurrence of basal rot of onion in Hokkaido. Ann Rept Plant Prot North Japan 25:33.

Komada H. 1975. Development of a selective medium for quantitative isolation of Fusarium oxysporum from natural soil. Rev Plant Prot Res 8:114-124.

Kondo N, Kodama F, Ogoshi A. 1997. Vegetative compatibility groups of Fusarium oxysporum f. sp. adzukicola and non-pathogenic Fusarium oxysporum on adzuki bean isolated from adzuki bean fields in Hokkaido. Ann Phytopathol Soc Jpn 63:8-12.

Larkin RP, Hopkins DL, Martin FN. 1990. Vegetative compatibility groups within Fusarium oxysporum f. sp. niveum and its relationship to virulence, aggressiveness, and race. Can J Microbiol 36:352-258.

Loffler HJM, Rumine P. 1991. Virulence and vegetative compatibility of Dutch and Italian isolates of Fusarium oxysporum f. sp. lilii. J Phytopathol 132:12-20. 
Lori G, Edel-Hermann V, Gautheron N, Alabouvette C. 2004. Genetic diversity of pathogenic and nonpathogenic populations of Fusarium oxysporum isolated from carnation fields in Argentina. Phytopathology 94:661-668.

Nelson PE, Tousson TA, Marasas WFO. 1983. Fusarium species: An Illustrated Manual for Identification. Pennsylvania: The Pennsylvania State University Pr.

Ploetz RC, Correll JC. 1988. Vegetative compatibility among races of Fusarium oxysporum f. sp. cubense. Plant Dis 72:325-328.

Puhalla JE. 1981. Genetic consideration of the genus Fusarium. In: Nelson PE, Tousson TA, Cook RJ (eds). Fusarium: Diseases, Biology, and Taxonomy. Pennsylvania: The Pennsylvania State University Pr. p 291-305.

Puhalla JE. 1985. Classification of strains of Fusarium oxysporum on the basis of vegetative compatibility. Can J Bot 62:540-545.

Simizu M, Nakano M. 1995. A method of field test for screening of onion varieties resistant to Fusarium oxysporum f. sp. cepae. Ann Rept Plant Prot North Jpn 46:78-80.

Summerell BA, Salleh B, Leslie JF. 2003. A utilitarian approach to Fusarium identification. Plant Dis 87:117-128.

Swift CE, Wicklffe ER, Schwartz HF. 2002. Vegetative compatibility groups of Fusarium oxysporum f. sp. cepae from onion in Colorado. Plant Dis 86:606-610.

Takehara T, Kuniyasu K, Mori M, Hagiwara H. 2003. Use of nitrate non-utilizing mutant and selective media to examine population dynamics of Fusarium oxysporum f. sp. spinaceae in soil. Phytopathology 93:1173-1181.

Thornton MK, Mohan SK. 1996. Response of sweet Spanish onion cultivars and numbered hybrids to basal rot and pink root. Plant Dis 80:660-664.

Vakalounakis DJ, Doulis AG, Klironomou E. 2005. Characterization of Fusarium oxysporum f. sp. radicis-cucumerinum attacking melon under natural conditions in Greece. Plant Pathol 54:339346

Venter SL, Theron DJ, Steyn PJ, Ferreira DI, Eicker A. 1992. Relationship between vegetative compatibility and pathogenicity of isolates of Fusarium oxysporum f. sp. tuberosi from potato. Phytopathology 82:858-862.

Woo SL, Zoina A, Del Sorbo G, Lorito M, Nanni B, Scala F, Noviello C. 1996. Characterization of Fusarium oxysporum f. sp. phaseoli by pathogenic races, VCGs, RFLPs, and RAPD. Phytopathology 86:966-973.

Woudt LP, Neuvel A, Sikkema A, van Grinsven MQJM, de Milliano WAJ, Campbell CL, Leslie JF. 1995. Genetic variation in Fusarium oxysporum from cyclamen. Phytopathology 85:1348-1355.

Yoo SJ, Watanabe H, Kobayashi K, Ogoshi A, Kodama F. 1993. Vegetative compatibility grouping of formae speciales of Fusarium oxysporum pathogenic to Liliaceae. Ann Phytopathol Soc Jpn 59:3-9. 